\title{
¿Cómo enfrentar los déficits sociales de América Latina?. Acerca de mitos, ideas renovadoras y el papel de la cultura
}

\author{
Bernardo Kliksberg*
}

\section{Resumen}

Este trabajo pretende llamar la atención sobre la necesidad de abrir y explorar sistemáticamente las vinculaciones entre situación social, posibles respuestas a la misma y marcos culturales de referencia. Para ello se analizan sucesivamente tres aspectos: a) tendencias del deterioro de la situación social de América Latina; b) mitos y estructuras de razonamiento que actúan como bloqueadores en la superación de los problemas, y c) posibles aportes desde lo cultural, a la problemática social. Se concluye que el gasto social en cultura, de acuerdo con la exploración ejemplificativa realizada, es realmente una "inversión social" de consecuencias multiplicadoras en gran escala para la solución de los graves problemas sociales de la región latinoamericana; especialmente si se aprovechan los modelos originales de autoorganización propios de la cultura milenaria de un continente mestizo, no sólo para la solución directa de los problemas, sino también para hacer efectiva la participación de la comunidad en la búsqueda de eficiencia y en el control social de la gestión de los programas sociales.

Palabras claves: cultura, desarrollo, gerencia social, participación comunitaria, pobreza.

Recibido: 02-10-96. Aceptado: 13-11-96

* Doctor en Clencias Económicas. Doctor en Ciencias Administrativas. Sociólogo. Asesor, entre otros organismos internacionales, de ONU, BID, UNESCO, UNICEF, OIT, OEA, OPS. Director del Proyecto de Naciones Unidas para América Latina de Modernización del Estado y Gerencia Social (1980-1994). Actualmente Coordinador General del nuevo Instituto Interamericano para el Desarrollo Social, creado por el BID en Washington. Autor de 32 obras y numerosos trabajos. Entre sus últimas obras se hallan: "Pobreza. Nuevas respuestas a nivel mundial", "Claves para una gerencia social eficiente", y "Social Management". 


\section{How to Face Social Deficits in Latin America? Myths, New ldeas and Culture Role}

\section{Abstract}

This paper attempts to call attention to the need to systematically open and explore the connections between the social situation, possible answers to the problems, and the cultural frame of reference. To do this, three succesive aspects are analyzed: a) tendencies towards deterioration in the Latin American social situation; b) myths and the structural reasoning processes which act as blocks to overcoming the problems; and c) possible cultural contributions for solution of social problems. The conclusion is that the social expenditures in culture, according to the exploratory examples studied, are really a social investment of multiple consequences on a large scale in the solution of severe social problems in the latinamerican region; especially if the original models of self auto-organization in this millenary culture of a mixed-race continent are taken into consideration, not only for the direct solution of those problems, but also to make the participation of the community more effective in the search for eficiency in the social control of the administration of social programs.

Key words: Culture, development, social administration, community participation, poverty.

\section{Replantear la agenda}

La situación social de América Latina es motivo actualmente de profunda preocupación. Los datos disponibles testimonian agudos déficits en incremento en áreas claves para la vida cotidiana de la mayoría de la población. Recientemente advirtió al respecto Shadid Javed Burki, Vicepresidente del Banco Mundial para América Latina: "América Latina es notable como una región en la que la pobreza, particularmente la pobreza absoluta, parece no registrar mejora alguna ... La proporción de personas en la pobreza absoluta en la región se incrementó entre 1987 y 1993". (Burki, 1996)

En el mismo sentido ha indicado Gert Rosenthal, Secretario General de la CEPAL, que la pobreza en América Lati- na creció en comparación con las décadas comprendidas entre los años 1950 y 1980. (Rosenthal, 1995)

El aumento de la magnitud y profundidad de los procesos de pauperización en la región, requiere un replanteo de fondo de los enfoques con que normalmente se ha analizado su evolución social. Hay demasiados vacíos a los que ellos no contestan, y surgen numerosas interrogantes sin respuesta clara. Ese replanteo es imprescindible para llegar a nuevas propuestas portadoras de innovación sustantiva en esta materia crucial.

Los resultados límitados de muchas de las políticas hasta ahora aplicadas están indicando insuficiencias severas en los marcos conceptuales en los que se apoyan. Este es un terreno donde, como ha sugerido Carlos Fuentes (1995), 
es imprescindible "pasar del cambio imaginado, a la imaginación del cambio".

Urgen abordajes que arrancando de análisis rigurosos de las causas del deterioro, lleguen a alternativas de acción efectivamente imaginativas.

Una de las dimensiones más marginadas en la discusión sobre el tema, es la del rol que puede jugar la cultura, en toda propuesta relevante de cambio. Las vinculaciones entre los procesos de implementación de políticas y programas sociales, y las condiciones y potencialidades culturales de las comunidades han sido muy limitadamente exploradas.

La cultura no aparece con frecuencia como un tema de la agenda de cambio en el que es posible apoyarse sino como una restricción u obstáculo externo que dificulta la aplicación de las políticas diseñadas.

Replantear la agenda supone, como una de las dimensiones a agregar a la misma, reintegrar el tema de la cultura en su plenitud.

Este trabajo se propone llamar la atención sobre la necesidad de abrir y explorar sistemáticamente las vinculaciones situación socialrespuestas posibles/marcos culturales. Su objetivo se halla autolimitado a presentar el tema para invitar a su indagación detallada. Para ello se recorrerán tres momentos de análisis sucesivos. En primer lugar, se trazará un perfil sumario de la situación social de la región. En segundo lugar se identificarán ciertos mitos y estructuras de razonamiento fuertemente anclados en las percepciones de grupos sociales de alta influencia que actúan como mitos "bloqueadores" en la superación de los problemas. En tercer término, se señalarán algunas líneas de trabajo sobre posi- bles aportes desde lo cultural a la problemática social.

\section{Tendencias en el campo social}

El análisis de la evolución de la situación social latinoamericana permite observar la presencia de ciertas tendencias de carácter inquietante, que por su vigor y persistencia, parecen sólidamente asentadas en aspectos estructurales de la realidad.

La Cumbre Presidencial de Miami (1994) llamó la atención sobre que "casi la mitad de la población del Hemisferio vive en la pobreza". Un informe cercano, producido por una Comisión de notables presidida por Patricio Aylwin y patrocinada por el BID, CEPAL y el PNUD (1995), indica luego de puntualizar diversos déficits sociales de consideración, que: "Los hechos descritos precedentemente que afligen, en mayor o menor medida, a casi la mitad de los habitantes de América Latina y el Caribe - pobreza, falta de trabajo, marginación social- constituyen un escándalo desde el punto de vista moral, son un obstáculo o freno al desarrollo e importan una peligrosa amenaza a la paz social y a la estabilidad política de nuestras naciones". En base a estas y otras fuentes internacionales, es posible identificar ciertas tendencias de desarrollo en la región, entre las cuales se hallan las que se indican sumariamente a continuación.

\section{- Crecimiento absoluto y relati- vo de la pobreza}

Las estimaciones disponibles indican un aumento del porcentaje de familias de la región ubicadas por debajo de 
la línea de pobreza. Asi las mediciones de la CEPAL, señalan que en 1980 dicho porcentaje era del $41,09 \%$, en 1986 habría ascendido al $43,5 \%$ y en 1990 se ubicaba en el $47 \%$.

En una población con fuerte crecimiento demográfico, ello significa junto al aumento de la pobreza relativa, un incremento considerable en las dimensiones absolutas de la pobreza. El número de pobres habría aumentado en 60 millones de 1980 a 1990.

\section{- Degradación de la "calidad" de la pobreza}

Las fuentes disponibles tienden a señalar que aumenta el segmento de la pobreza que ingresa en la clasificación de "pobreza extrema". Se incluye en dicha categoría a las familias que si gastaran todo el ingreso que reciben exclusivamente en comprar alimentos, hipótesis irreal dado la imprescindibilidad de otros consumos, igual no les alcanzaría para adquirir el mínimo de proteínas y calorías necesarias. Ese grupo de población ha aumentado su proporción en el total ubicado por debajo de la línea de la pobreza. Tiene aguda expresión física en el crecimiento de las áreas marginales en los principales centros urbanos de la región.

\section{- El carácter discriminatorio de la pobreza hacia los niños}

Las tendencias en curso han llevado a una acentuación de la pobreza en el sector más débil de la población, los niños. Según resaltó recientemente Carol
Bellamy, Directora Ejecutiva de UNICEF, de un total de 237 millones de niños menores de 16 años, 118 millones son pobres. La tercera parte de ellos se halla en la indigencia. 600.000 niños perecen anualmente por causas que podrian evitarse. Bellamy sintetiza la situación destacando que: "los niños llevan la peor parte de la pobreza y del extremo desequilibrio en la distribución de la riqueza que existe en casi todo el hemisferio". (Bellamy, 1996)

Estas realidades discriminatorias se expresan en múltiples planos. La OIT ha llamado a alarma por el aumento acelerado de la mano de obra infantil en el área. Ha estimado que en 1990 existian en ella 20 millones de niños trabajadores menores de 14 años. Esa situación contravenía las legislaciones y compromisos internacionales vigentes, los dejaba fuera del sistema escolar o los inducía a la deserción, y los sometía a condiciones de vida deteriorantes. Por otra parte ha aumentado continuamente la población de niños en situación de riesgo, que viven en las calles de grandes ciudades de América Latina, en medio de cuadros de vida lóbregos, y peligrosos. Al mismo tiempo resultan preocupantes los indicadores de desnutrición. La UNICEF plantea que es necesario rescatar de la desnutrición a unos 6 millones de niños. Una expresión de la regresividad de los procesos en marcha en ese plano es que a pesar de los avances médicos, los especialistas en nutrición han identificado en algunos países y áreas, una reducción de los pesos $y$ tallas de los niños al nacer. 


\section{- La "feminización de la pobre- za"}

Otro sector de población particularmente afectado por los déficits sociales es el de las mujeres humildes. Ha crecido fuertemente en la región el número de hogares de recursos limitados con un solo cónyuge, la mujer, al frente del mismo. En la casi totalidad de los países, los hogares con jefatura femenina superan al $20 \%$ del total de hogares, y se observa un ascenso significativo en este indicador. En los hogares modestos eso implica condiciones de vida mucho más duras para la mujer. Debe al mismo tiempo que trabajar intensamente, desarrollar las tareas del hogar, y llevar sobre sí el peso de los dos roles básicos del marco familiar. Por otra parte, su trabajo se lleva a cabo normalmente en condiciones de discriminación salarial y ocupacional, y bajo el peso de fuertes estereotipos y prejuicios adversos. Los hogares a cargo de una mujer, tienden según los estudios existentes a presentar índices de pobreza relativa mayores.

La mujer rural, asimismo, registra agudamente el impacto de la pobreza. A las condiciones sociales desfavorables, se suman marcadas discriminaciones culturales, y se produce entre otros aspectos una intensa exclusión del sistema educativo. Es restringida o dificultada su asistencia a la escuela. En extensas zonas las tasas de analfabetismo de las mujeres campesinas superan ampliamente a las tasas promedio, $y$ a las masculinas.

\section{- Empleo e ingresos}

Según indican numerosos análisis, las condiciones básicas de empleo e ingresos de buena parte de la población de la región han experimentado severas dificultades en los últimos 15 años. Entre los principales procesos en curso se observan los que siguen:

a. Entre 1980 y 1992 disminuyó constantemente el empleo en el sector moderno. Entre otros testimonios coincidentes al respecto, destaca Oscar Altimir que si bien ha crecido la productividad en empresas medianas y grandes en los últimos años, el em. pleo en ese segmento se ha reducido en más del $3 \%$ anual.

b. Se ha degradado seriamente la calidad de los empleos. Según las estimaciones de Víctor E. Tokman 8 de cada 10 empleos creados desde 1980 fueron generados en el sector informal.

El empleo total en dicho sector pasó de significar el $40,6 \%$ de la mano de obra ocupada no agrícola en 1980, a representar el $55,7 \%$ de la misma en 1995. (Tokman, 1996)

El empleo informal conformado entre otras ocupaciones por el cuentapropismo, los servicios personales, los servicios domésticos, la buhonería y formas de intermediación semejantes, etc., se caracteriza por su inestabilidad, precariedad, baja productividad, y limitados ingresos. Se estima que la productividad promedio en ese sector es de una tercera a una cuarta parte de la productividad en el sector moderno. Asimismo, los informales carecen virtualmente de protección social.

c. En este marco de dificultades laborales serias, los ingresos de los asala- 
riados y de los informales han tendido a reducirse marcadamente. Los salarios mínimos reales descendieron de un indice de 100 en 1980, a 70,1 en 1995. En la década de 1980 al 90 , los asalariados de las empresas medianas y grandes perdieron el $7 \%$ del valor real de su salario, los que traba. jaban en empresas pequeñas $y$ el sector público el $30 \%$ de su salario real. El ingreso de los informales se redujo en esa década en un $42 \%$.

d. En el caso de quienes han mantenido sus trabajos se observa según indica Alfredo Costa Filho debilitamientos en sus condiciones laborales como: "corte de horas extras, reducción de beneficios asociados a adiestramien. to, maternidad/paternidad, vacaciones, fomento de la dimisión voluntaria, baja de contribuciones sociales del empleador, regímenes de media jornada, etc.". (Costa Filho, 1995)

e. Además de incrementarse las tasas de desocupación ha subido el período promedio de duración de la misma.

f. Un caso elocuente ilustrativo de otros es el de los servicios públicos. Su peso en la mano de obra total no agricola, con mucha frecuencia sobreestimado era en 1980 de $15,7 \%$. Pasó en 1995 a representar el $13,6 \%$. Pero además de la pérdida de puestos de trabajo el deterioro en los niveles salarios reales mínimos y promedio fue de tal significación, que se ha estimado que actualmente cerca del $20 \%$ de los empleados integran hogares ubicados por debajo de la línea de la pobreza. (Costa Filho, 1995)

Los procesos señalados conforman un cuadro donde una buena parte de la población supuestamente ocupada integra un "circuito informal" caracterizado por ocupaciones inestables, baja productividad, imposibilidad de absorber tecnologia avanzada, bajos ingresos. Se hallan inmersos en una "precarización" que a su vez transmiten a la generación siguiente.

Las perspectivas que se ofrecen a amplios sectores de las nuevas generaciones oscilan entre la "precarización" señalada y la desocupación ablerta. Las tasas de desocupación juvenil abierta han crecido fuertemente en toda la región, y tienden a sobrepasar el $20 \%$.

\section{- La irrupción de los "nuevos pobres"}

Junto a la pobreza conformada históricamente en la región, y a los denominados "pobres estructurales" aparecen hoy contingentes crecientes de sectores de las clases medias en "picada" que se caracterizan con la categoría de "nuevos pobres".

Se trata de grupos sociales que por la estabilidad de su ocupación, el prestigio de la misma, los ingresos que reportaba, sus acumulaciones previas en campos como la educación, la cultura, y la misma vivienda formaban parte de la clase media, y ahora están experimentando serias crisis en todos esos planos.

Entre ellos se hallan funcionarios públicos como maestras, enfermeras, empleados de línea, cuyos ingresos han perdido buena parte de su valor adquisitivo, pequeños comerciantes e industriales, que están marcando récords de quiebras y convocatorias, empleados administrativos de empresas de diversa índole 
también con ingresos reales en baja, jubilados cuyos haberes se han visto mermados seriamente en términos de capacidad de compra efectiva, buena parte de las profesiones liberales antes "pasaje" a la clase media y ahora con graves dificultades ocupacionales.

Diversos indicadores directos e indirectos dan cuenta del crecimiento de este grupo social. Entre ellos, Alberto Minujín estima que en el caso argentino significaban en 1990 el $18,4 \%$ de la población cuando en 1974 casi no tenian existencia estadistica. (Minujin, 1995) Recientemente este amplio sector social llevó a cabo una "huelga de deudores bancarios" en México frente a la imposibilidad de afrontar préstamos contraídos ante los desequilibrios de empleo e ingresos que se presentaron en sus realidades. Se ha estimado, que medida con criterios estrictos, $30 \%$ de la cartera de créditos de los bancos mexicanos tiene más de tres meses de atraso. (Anderson, 1996) En Venezuela se calcula que la clase media se redujo en un tercio en los últimos 25 años. (New York Times, 19-02-96)

Los "nuevos pobres" tiene rasgos sociológicos muy particulares. Ante todo no se reconocen como un sector social especifico. Mantienen los valores propios de la clase media. Tratan a veces de "esconder" su nueva pobreza, que no es coherente con dichos valores. Han debido en muchos casos trasladarse de la escuela privada que no pueden ya pagar a la pública, y de la salud privada a los servicios generales. Sienten un profundo "desarraigo social" ante esta crisis producida en un periodo de tiempo rápido, cuyos orígenes no pueden explicarse con facilidad y que tienden con frecuencia a atribuir a errores personales de ellos mismos.

\section{- El debilitamiento de la unidad familiar}

Se está produciendo en el marco de situaciones descritas un serio deterioro en las bases de la institución "fortaleza" de cualquier tejido social, la unidad familiar. La familia, de acuerdo a evidencias múltiples, tiene roles insustituibles para la "salud" de la sociedad. Su papel de formadora de valores de los niños, de protección a su maduración afectiva, de cuidado directo de su desarrollo sano, de ayuda y sostén del proceso educativo de la escuela, de marco de pertenencia básico, y otros roles de una lista muy amplia y abierta, la convierten en célula esencial del tejido social. Por ejemplo, como se señala hoy con frecuencia en economia, no hay ningưn sistema de protección social que supere su eficiencia, ni produzca una relación input/output mayor.

En la región hay un serio proceso de debilitamiento de la familia particularmente agudo en los sectores pobres, fuertemente influido por las circunstancias antes caracterizadas. El crecimiento antes señalado de los hogares humildes en los que la mujer queda sola al frente de los mismos, es indicativo de este proceso. Su otra cara, es la "deserción" del hogar, de los maridos. Este último sector ha sido limitadamente estudiado. ¿Por qué se produce el "abandono", qué razones de fondo determinan una tendencia consistente de esta magnitud? En un trabajo pionero Rubén Katzman (1992) construye un relevante cuadro de hipótesis. Sintéticamente, se plantea que el 
jefe de hogar pobre siente en primer lugar que no puede cumplir un rol fundamental que se espera de él: proveer buena parte de los ingresos del hogar. La precarización, y la desocupación combinadas le dejan limitado margen al respecto. Al mismo tiempo la presencia de los medios masivos en cada rincón de la sociedad, "excita" a las familias de todas las condiciones a aspirar como pautas de consumo, a las que exhiben los medios, típicas de la clase media. Esa presión se desata también en las familias humildes. El jefe de hogar se encuentra sin ocupación estable ante expectativas crecidas. Como consecuencia, siente que pierde diariamente "legitimidad" en su papel. Asimismo que uno de sus roles principales el de servir de "modelo de referencia" a sus hijos está cuestionado casi totalmente. Su imagen se devalúa ante su entomo familiar, y ante él mismo. Entra en situación "cuasianómica", y percibe las dos posibilidades clásicas en casos de stress hipertenso. El enfrentamiento de los problemas para lo que no ve caminos, o la "fuga". La "deserción" del hogar parece tener fuertes raíces en este "círculo sin salida".

El deterioro de la familia va a repercutir sobre el desarrollo del niño en múltiples planos desde el directamente biológico, hasta el intelectual, afectivo, y moral. Inducirá, como lo demuestran diversos estudios al respecto, entre otras consecuencias un menor rendimiento escolar, o impulsará hacia un abandono rápido de la escuela.

\section{- El ascenso de la violencia}

Las sociedades latinoamericanas enfrentan actualmente un serio problema de ascenso de los índices de criminalidad y del clima de inseguridad. Estudiando rigurosamente el problema Luis $\mathrm{C}$. Ratinoff indica que se considera que un esce. nario de incidencia del delito moderado controlable con estrategias normales es el 0,5 a 5 homicidios violentos anuales por cada 100.000 habitantes. De 6 a 8 por 100.000 se ingresaria en un escenario donde las estrategias convencionales tendrían aplicación limitada. Por arriba de ese umbral en la conversión de la violencia en un "fenómeno epidémico", con subculturas que la practican a su interior, y gravísimos daños sociales. La tasa latinoamericana ha venido creciendo y se ubica actualmente en un 20 por 100.000 .

Los costos sociales, económicos, y existenciales, de este nivel de delito son altísimos. Por otra parte, de acuerdo a los datos existentes, la delincuencia tiende a concentrarse en edades cada vez más jóvenes. Las causas de su aumento son complejas, y están en exploración. Claramente guardan relación con muchos de los procesos antes mencionados. Entre ellas, destaca como el último cuadro reseñado, el debilitamiento de la familia, que puede estar privando a la sociedad de la principal fuente de regulación del comportamiento con que cuenta. La "anomia familiar" dificulta la transmisión a las nuevas generaciones de valores esenciales para trazar fronteras, y prevenir conductas delictivas.

El conjunto de déficits de diverso orden referenciados funciona interrelacionadamente generando un "círculo perverso de exclusión". Se van dando hacia el interior de la sociedad "profecías que 
se autorrealizan". El circuito de carencias nutricionales, crisis familiar, y deserción educativa, conducen a imposibilidad de competir en el mercado laboral, al desempleo y a la precarización, que se transmiten hacia las generaciones siguientes. Los "excluidos", que de acuerdo a las estimaciones no son una minoría sino casi la mitad de la población, no forman parte de la fuerza de trabajo regular, $y$ tienen una participación errática como consumidores en el mercado.

El Informe Aylwin retrata así la sjtuación: "La pobreza genera marginalidad y esta alimenta la pobreza. En realidad los pobres no participan en la vida económica, ni en la social, ni en la política. Están excluidos del mercado y su presencia política o su influencia social se mantienen en el plano formal antes que en el real... En realidad al excluir a los pobres de la economía y de la sociedad se les niega el derecho de luchar para liberarse de su pobreza. (BID, 1995)

\section{Acerca de mitos y estructuras de razonamiento "bloqueadoras"}

Los agudos problemas sociales que se presentan en la región, son totalmente contradictorios con su elevado potencial natural de recursos económicos. Se trata de una zona dotada de enormes posibilidades en campos que van desde los minerales estratégicos, hasta fuentes de energía de toda índole, y excelentes condiciones agropecuarias.

Es necesario buscar las explicaciones en la historia socioeconómica de América Latina, en su modo de inserción en la economía internacional, en los errores cometidos en la elaboración de políticas, y otros campos conexos. En cualquier análisis será útil ver el papel activo que en la dificultad de concebir e impulsar soluciones renovadoras han tenido ciertos mitos y estructuras de razonamiento fuertemente influyentes, que "bloquean" los caminos hacia su encuentro.

Trataremos a continuación de poner a foco esquemáticamente algunos de ellos.

\section{- La teoria del derrame}

Se ha ofrecido con frecuencia a las sociedades la visión de que el esfuerzo debía centrarse en ciertas metas macroeconómicas que automáticamente conducirian a la solución del conjunto de problemas sociales en etapas posteriores. La realidad indica la imprescindibilidad de que los países crezcan a fuertes tasas, obtengan equilibrios macroeconómicos, aseguren la estabilidad, y mejoren su competitividad. Sin embargo, la suposición de que por sí el crecimiento se "derramaría" hacia el conjunto de la población, y que se trata en definitiva de un problema de "tiempo y paciencia histórica", se ha demostrado infundada. El análisis hecho por el sistema de Naciones Unidas en sus Informes de Desarrollo Humano sobre la experiencia de 130 países en las últimas décadas indica que las interrelaciones entre desarrollo económico y desarrollo social son muchos más complejas que la versión sugerida desde la teoría del derrame. Las hipótesis centrales de la misma no han funcionado virtualmente en ningún caso. Si no me- 
dian interconexiones activas y sistemáticas entre lo económico y lo social esta última área permanecerá sin soluciones. Los paises que han logrado resultados en ambos campos se han caracterizado por superar la visión simplista del derrame, y avanzar hacia una activa política "socioeconómica".

\section{- La perspectiva reduccionista del desarrollo}

¿Cuáles son las "palancas" del desarrollo? En la región se ha tendido a poner el acento en la acumulación de capital, como un eje central del mismo, y en la postergación de otras formas de gasto o inversión para privilegiar dicha acumulación. Sin embargo, el desarrollo se ha demostrado como un proceso mucho más multifascético en la experiencia histórica reciente. El Banco Mundial distingue actualmente cuatro formas de capital. Se halian los activos naturales, recursos con que un país cuenta como dotación natural. Otra forma son los activos construidos, creados por la labor de dicha sociedad que incluyen, entre otras dimensiones, los activos fijos, las infraestructuras, el capital financiero, el capital comercial. Pero junto a ellos hay otras dos formas de capital, el capital humano conformado por la calidad de la población, en aspectos claves como nutrición, salud, y educación, y el capital social. Esta última categoria hace referencia a que toda sociedad tiene determinado acervo en términos de valores, cultura, grado de inteligencia de sus instituciones. Deberla agregarse a ello aspectos intangibles, pero de gran peso como el "stock de redes de cooperación" con que cuenta una sociedad a su interior, y la capacidad de generar permanentemente redes que entrelacen los esfuerzos de sus actores en relación a metas de interés colectivo. Asimismo su "pluralismo organizacional", es decir la existencia de múltiples formas de organización que le den la mayor flexibilidad posible para contestar a diferentes desafíos. En las visiones de desarrollo de fines de este milenio, se está revalorizando el peso de estas dos últimas formas de capital. Recursos humanos, y capital social parecen dos palancas formidables del desarrollo.

La experiencia de las sociedades que han invertido sistemática y consistentemente en recursos humanos y en algunos casos en formas del capital social y ahora están obteniendo resultados totalmente diferenciales respecto a otras en términos de progreso tecnológico y competitividad así lo indica. Entre ellas, con heterogeneidad de situaciones se hallan países que han logrado simultáneamente buenas metas de progreso económico y desarrolio social, como Canadá, los paises nórdicos, Holanda y Bélgica, Japón, los tigres asiáticos e Israel.

No solamente el crecimiento económico de por sí no soluciona los problemas sociales, sino en la nueva visión en expansión, la falta de inversión social impide el crecimiento económico sostenido. Indica al respecto James Wolfensohn, Presidente del Banco Mundial: "Sin desarrollo social paralelo no habrá desarrollo económico satisfactorio". Amartya Senn (1996), prominente autoridad en el tema social, plantea en un reciente trabajo que ha habido al respecto errores de fondo en 
la concepción -que denomina de "sangre, sudor y lágrimas"- que se "sobrevendió" al mundo en desarrollo. Desde esta concepción tan difundida en América Latina se reclaman enormes sacrificios en lo social al servicio de un futuro supuesto de prosperidad expansiva. Pero, señala el catedrático de Harvard, la realidad indica que hay profundas interdependencias entre el desarrollo humano, y la expansión de las capacidades productivas. El crecimiento y la productividad están ligados a la inversión en nutrición, salud, educación, y rubros semejantes. Por ende los sacrificios referidos pueden minar las bases de un crecimiento sostenido.

\section{- El relegamiento del tema de la inequidad}

Estructuras de razonamiento de fuerte peso en la región han relegado de la agenda de discusión el tema de la inequidad. En algunos casos considerándolo marginal a los grandes debates sobre las líneas del desarrollo. En otros, sugiriendo que en definitiva un fuerte grado de inequidad formaría parte del "Sangre, sudor y lágrimas" necesario para que se produjera la acumulación de capital planteada.

La experiencia de los "países exitosos" ha seguido un camino casi opuesto. Han tendido a ubicar el problema en el centro de la agenda, y a desarrollar politicas consistentes de mejoramiento de los niveles de equidad. Los resultados diferenciales en uno y otro caso son muy indicativos. Un riguroso trabajo economé- trico de Birdsall, Ross y Sabot, "La desigualdad como restricción al crecimiento en América Latina" (Birdsall, 1996a) explora la evolución de los indicadores de inequidad en América Latina y el Sudeste Asiático en las últimas cuatro décadas. Mientras que en la primera región la inequidad ha seguido pronunciándose, hasta convertirse hoy según estimaciones en la región más desigual del mundo, en el Sudeste Asiático ha habido un esfuerzo sistemático por mejorarla.

En tanto la polarización entre el $20 \%$ de población, ubicada en los estratos superiores, y el $20 \%$ más bajo, se redujo a 4,2/1 en Taiwan, a 8/ 1 en Corea, $y$ es de $4 / 1$ en Noruega, creció a 27/1 en Brasil, a 26/1 en México, y ascendió en toda América Latina. La inequidad se paga caro, además de socialmente, en términos de eficiencia macroeconómica. El mejoramiento de la equidad, a través de diversas reformas entre otros aspectos de educación de buena calidad generalizada, fue base en el progreso del Sudeste Asiático. Asimismo fue obstáculo grave en América Latina. Entre otros aspectos según indican los autores, reducir la desigualdad estimula el crecimiento por las siguientes vías:

* Contribuye a la estabilidad política y macroeconómica.

* Incrementa la eficiencia de los trabajadores de bajos ingresos.

* Hay una menor brecha entre los ingresos rurales y los urbanos to que genera diversos efectos económicos beneficiosos.

* Reduce la necesidad de institucio- 
nes reguladoras que operen en este campo.

\section{- El gasto social: ¿gasto o inver- sión?}

Varios mitos fuertemente arraigados en el medio latinoamericano caracterizan la realización de programas en el campo social como un "gasto", le asocian características de "concesión" a "presiones clientelares", o "compensación" para atenuar impactos, y finalmente adjudican una especie de "ineficiencia congénita" a su gestión. Se trataría por tanto de un gasto casi improductivo, necesariamente destinado a la ineficiencia, y que estaría en consecuencia distrayendo recursos de usos más útiles para la economía.

Funcionando en el marco de parámetros culturales de ese tipo, el gasto social pierde credibilidad y los programas respectivos, serian en definitiva "ilegítimos".

A nivel internacional, la mitología ha sido totalmente superada, y las preocupaciones son otras. Se señala continuamente por ejemplo que una de las inversiones más rentables en el mundo hoy es dedicar recursos a la educación de las niñas jóvenes, porque aumentar su capital cognoscitivo va a incidir fuertemente en sus pautas de fertilidad, $y$ en sus capacidades para manejar etapas cruciales como el preparto, el parto mismo, y la lactancia. El Banco Mundial señala que tres años más de escolaridad de las madres pueden reducir la mortalidad infantil en un 15 por mil. Asimismo se demuestra que un campesino con educa- ción primaria completa tiene una productividad superior en un $70 \%$ al que no la ha completado.

Las ideas que se manejan son que lo social es una inversión, no un gasto. Que es una prioridad y no sólo para el sector público sino para toda la sociedad. Que todos los actores sociales en conjunto deben sumar esfuerzos para invertir recursos adecuados en la materia. La preocupación es mejorar crecientemente la calidad de esta inversión, y aprender de programas sociales gerenciados con excelencia las claves de sus éxitos. Nancy Birdsall sostiene al respecto: "Los programas en educación y salud pueden parecer consumos, pero en realidad buenos programas son inversiones en las capacidades, productividad, y futuros ingresos de la gente". (Birdsall, 1996b)

La mitología circulante en la región al respecto dificulta seriamente concentrar esfuerzos en mejorar la calidad de la gerencia social, que debería ser el tema, y los desvía hacia la negación y descalificación del gasto social.

La reducción continua del gasto social que se ha producido en la región, con frecuencia "racionalizada" por esa ideología, ha incidido en deterioros severos en áreas donde por las dificultades económicas la demanda de la población crecía. Así se estima que con excepción de la seguridad social, el gasto real per capita bajó en América Latina entre 1980 y 1990 en todos los rubros. Con indice 100 en 1980 , era en 1990 en educación 83,7 , en salud 94,8 , en vivienda 66,6 en otros 
servicios (subsidios, agua, gastos regionales, etc., 67,2). (Cominetti, 1994)

\section{- La cultura, un área ajena al de- sarrollo}

Los mitos circulantes dan todavia un lugar aún más secundario que el gasto social tradicional, a las asignaciones a cultura. Habría una especie de desvinculación cuasitotal entre cultura y desarro11o. Se trataría de un campo ajeno a los esfuerzos por mejorar la economía, e incluso a la política social. Un área que por ende, no tendría por qué figurar en la agenda mayor de los temas del desarrollo, y sería relegable para otra etapa cuando se hubieran cubierto ampliamente las metas trazadas. Estos mitos, que no logran captar los roles claves que juega de hecho la cultura, en los esfuerzos por el desarrollo, llevan mecánicamente a su marginación en las agendas, $y$ en las asignaciones presupuestarias.

\section{- La renuncia a la solidaridad}

Un reciente añadido de gran trascendencia a la mitología circulante es la reacción frente a las realidades de la exclusión social de amplios sectores de población antes consignadas, en términos de "razonamiento fatalista". La polarización, la inequidad acentuada, y la exclusión, serian fenómenos inevitables, y las sociedades latinoamericanas estarían predestinadas a conformarse con un porcentaje de población reducido con todas las posibilidades, y un gran número con niveles de vida precarios en pobreza, o indigencia. Tras este mito, habria subyacente una idea fuerza mayor: la renuncia expresa a la solidaridad. Ella no estaria acorde con los tiempos históricos. Sería una concepción prescindible.

\section{- La marginación del tema del perfil de sociedad}

Una gran exclusión del debate es con frecuencia la de revisar hacia dónde va el perfil mismo de sociedad. Cada una de las concepciones analizadas, de los mitos mencionados, $y$ las estructuras de razonamiento operantes, tiene impactos en términos de perfil de sociedad.

La teoría del derrame implica así, lanzar generaciones a fuertes carencias, bajo la promesa de un escenario que automáticamente será mejor para las siguientes. La visión reduccionista del desarrollo significa dar un rol menor a los recursos humanos, e ignorar parte fundamental de la creación de una sociedad, como lo es la generación y acumulación del capital social. el relegamiento de la inequidad, implica saltear el "stress social" agudo que vivirá la misma como consecuencia de ella. La desvalorización del gasto social, lleva a cerrar apoyos en momentos de mayor necesidad. La renuncia a la solidaridad, es casi una opción por determinado perfil de sociedad, donde los derechos humanos básicos estarían fuera del alcance de vastos sectores de las mismas. Tendrían garantizados derechos ciudadanos, pero no derechos sociales elementales como el derecho al 
Déficits sociales, cultura y eficiencia

Bernardo Kliksberg

empleo, la salud, y la educación entre otros.

Este tema resulta insoslayable en cualquier perspectiva de análisis. El perfil que vaya adquiriendo la sociedad será el hábitat donde se llevarán a cabo los esfuerzos por el desarrollo económico, social, y el fortalecimiento democrático. Si ese perfil resulta conflictivo y contradictorio con esos esfuerzos, los mismos carecerán de sustentabilidad. Una sociedad dominada por mitos y razonamientos que legitiman mecanismos como el sacrificio de generaciones, el aumento de la inequidad, la desvalorización de la cultura, entre otros, generará intensas tensiones que reducirán los umbrales de gobernabilidad democrática. La inestabilidad y los costos directos de las privaciones e inequidades comprometerán las posibilidades de crecimiento económico sostenido y la competitividad de la economía.

Por otra parte como lo destaca Amartya Senn el perfil de sociedad es en última instancia un fin en símismo. Define la calidad de la vida de sus miembros. Como ejemplifica invertir en educación femenina, además de ser productivo macroeconómicamente y deseable en términos de desarrollo social, significa contribuir a cambiar la discriminación de género vigente, y por ende a avanzar en la calidad de vida global de la sociedad.

Entre las causas principales que han bloqueado la solución de los graves problemas sociales que hoy registra la realidad de la región, se hallan mitos y modelos de razonamiento como los señalados.

Avanzar en el camino del desarrollo social va a requerir un enorme esfuerzo colectivo de superación de estos "bloqueos" y progreso en dirección a concepciones renovadoras. Entre los temas que requieren "aire fresco" se halla el del rescate de la cultura para los esfuerzos por solucionar los problemas sociales. A continuación se pone a foco esa interrelación.

\section{Cultura y desarrollo social: una agenda para la acción}

Desde la perspectiva de los mitos y estructuras de razonamiento del tipo de las identificadas, la labor en el campo cultural tiende a ser percibida con "estereotipos" bien definidos. Es una actividad "puro gasto", sus resultados son difícilmente medibles, no tiene una "tasa de retorno sobre la inversión" clara, su gestión sería realizada con alta ineficiencia. En definitiva, desde este enfoque su grado de legitimidad social es bajo y no puede esperarse mucho de sus contribuciones a problemas como los sociales.

Con frecuencia la cultura es percibida a partir de estos parámetros no como "oportunidad" sino como "obstáculo". Aparece y reaparece como tal en los intentos por llevar adelante desde arriba los programas sociales que la comunidad "no sabe que necesita", pero son los necesarios. Dificulta la ejecución de los mismos. Crea problemas inesperados.

La mitología no coincide en este campo como en otros, con los hechos observables. La cultura comienza a ser releída con fuerza creciente como una parte central del capital social de una sociedad. Se registra que los paises que han sabido apoyarse en ella, y potenciar- 
la, han generado a partir de la misma modelos organizacionales inéditos, conocimiento nuevo, redes de cooperación interna potentes. Todo ello, ha enriquecido su perfil como sociedades y simultáneamente ha mejorado su "calidad de pais" y su competitividad. Entre otras posibilldades la cultura puede realizar aportes fundamentales al desarrollo social. Los valores, las actitudes, las tradiciones, a favor de la cooperación, la solidaridad y el voluntarismo, que presenta la cultura de ciertos países, se hallan en la base de sus logros en materia de creación de una sociedad civil fuerte y diversificada.

Así, la multiplicidad de organizaciones voluntarias de trabajo social en países como Canadá, Suecia, Noruega, Dinamarca, Finlandia e Israel entre otros, tiene una raiz central en el impulso que desde la cultura surge permanentemente para esos desarrollos. Un estudio sobre el voluntarismo en Israel indica que el $25 \%$ de la población realiza tareas voluntarias, generando servicios principalmente sociales que constituyen el $8 \%$ del Producto Bruto Nacional. En 1984 había 3186 organizaciones voluntarias registradas, en 1991 habian pasado a 15.000. La explicación de la fortaleza del voluntariado la encuentra el estudio principalmente en la cultura: "Los textos y las tradiciones hebreas pusieron el énfasis en el deber de servir a Dios y al prójimo como precepto al que quedan obligados todos y cada uno... La cultura judia lleva en su médula los deberes de dar y de hacer para mejorar la realidad". (Faigon, 1992)

Los cambios desfavorables en el campo de la cultura pueden hacer retroceder los logros obtenidos. Así analizan- do el panorama en los EEUU donde a fines de los 80 el amplio movimiento de voluntarios y entidades no lucrativas ocupaba el $6,5 \%$ de la fuerza de trabajo, Robert Putnam indica que las asociaciones voluntarias llegaron a su cúspide una generación atrás, cuando la política y las actividades públicas tenian mayor prestigio. Según sus investigaciones ha habido cambios en la cultura, entre ellos la mayor dedicación de tiempo a la televisión que constituye un responsable fundamental en el desplazamiento de parte de la labor voluntaria. (Cit. por Kuttner, 1996)

Frente a la agenda de problemas sociales que presenta la región, la cultura no sólo no es un obstáculo, sino que puede ser un aliado formidable para la nueva generación de políticas sociales que hoy se requiere. Entre otras áreas de interrelación que deberian explorarse sistemáticamente, extrayendo consecuencias en términos de acción, se pueden identificar en nómina principalmente ilustrativa las siguientes:

a. La población pobre tiene un importante capital cultural que movilizado puede generar respuestas muy creativas $y$ acordes a su realidad $y$ a sus problemas de supervivencia. América Latina ofrece múltiples ejemplos de ese tipo. Uno de los más característicos es el de Villa El Salvador del Perú. Esta vasta experiencia social protagonizada por más de $\mathbf{2 5 0 . 0 0 0}$ habitantes marginales de Lima, llegados en su mayor parte de la sierra peruana, se inició en la más absoluta indigencia de recursos, y se ha convertido por sus logros en un modelo de referencia internacional. UNESCO premió a Villa El Salvador como una de las más desafiantes 
Déficits sociales, cultura y eficiencia Bernardo KIIksberg

experiencias en educación popular, las Naciones Unidas como una promotora ejemplar de formas de vida comunitaria. El Gobierno de España le otorgó el Premio Príncipe de Asturias por el impresionante desarrollo alcanzado por esta comunidad en el área social y cultural. Partiendo de la miseria, instalados en arenales inservibles en las afueras de Lima, los miembros de la Villa llevaron a cabo en un periodo de tiempo limitado un gigantesco esfuerzo de autoconstrucción colectiva en múltiples terrenos, basado en la movilización de sus propias capacidades latentes. Satisfacieron las necesidades alimentarias esenciales, dieron cobertura de salud a toda la población, tienen tasas de matriculación del $87 \%$ de los niños en primaria, y del $95 \%$ de los jóvenes en secundaria. Su índice de analfabetismo es del $3,5 \%$ mucho menor a la media nacional, lo mismo que sus tasas de mortalidad infantil, y bruta. Construyeron más de 50.000 viviendas, convirtieron parte del arenal en tierras cultivables, pusieron en funcionamiento un parque industrial de microempresas.

En la base de sus progresos se halla la generación a partir de la cultura de solidaridad y cooperación que trajeron de los Andes de fórmulas de autogestión $y$ trabajo en común casi inéditas. Al interior de la Villa fundaron más de 4.000 unidades organizativas que trabajan sobre todos los problemas de los habitantes de la misma. En el centro de su cultura se halla lo que los analistas denominan "su explícita autodefinición como una comunidad urbana autogestionaria centrada en el desarrollo de valores comunitaris- tas, autogestores y participativos". (Franco, 1992)

Junto a los modelos originales de auto-organización, la cultura milenaria de la que son portadores, contribuyó incluso con "herramientas técnicas" muy concretas. Las "lagunas de oxidación" inventadas por los Incas para recoger los desechos, les permitieron transformar los mismos en abonos con los que crearon "verde" en zonas casi descartadas.

La misma atmósfera de creatividad social desde la propia cultura acompaña a otras experiencias de la región, como la de marginales en centros urbanos del Brasil, campesinos indigenas en Bolivia, y madres pobres a cargo de hogares de cuidado diario en Colombia y Venezuela, entre muchas otras.

La cultura de los pobres es capital social que potenciado puede servir de base de respuesta para problemas sociales esenciales. La tecnología doméstica, los saberes, las costumbres, las capacidades innatas de auto-organización existentes en sus culturas pueden contribuir a soluciones innovadoras y adecuadas a sus realidades en educación, salud, agricultura, construcción, y otras áreas.

b. La actividad cultural puede constituir un instrumento maestro para la promoción de la articulación social. El fortalecimiento de dicha articulación resulta a su vez una condición clave para que las comunidades humildes puedan participar en forma real y efectiva en el diseño y la gestión de los programas sociales, con todos los beneficios que ello implica en términos de acercamiento de los mismos a sus necesidades, eficiencia de su fúncionamiento, y control social de su mar- 
cha. La deseada y tan convocada actualmente participación de la comunidad requiere de un tejido social fuerte. La creación de espacios culturales, y la labor común en cultura, pueden ayudar significativamente en ese plano.

c. La labor cultural puede aportar elementos relevantes al fortalecimiento de la unidad familiar. En dicha labor las familias pueden encontrar apoyos para algunos de sus problemas, y fuentes de estímulo. Pueden asimismo encontrar valores y tradiciones que reforzarán sus mecanismos de defensa para proteger la familia, asediada por las condiciones externas desfavorables mencionadas con anterioridad.

d. La acción cultural puede ser un factor crucial en mejorar la autoestima de la población pobre. El cultivo de una identidad cultural fuerte y productiva, puede dar elementos de autorreconocimiento cruciales frente a las situaciones de desvalorización permanente que afrontan. La elevación de la autoestima colectiva e individual, puede a su vez ser un motor poderoso para el redoblamiento de sus luchas y la concepción de nuevas iniciativas. Este rol de los valores de la cultura como proporcionadores de autoestima aparece con toda fuerza en Villa El Salvador. Señalan los investigadores: "cuando se asiste con alguna frecuencia a reuniones de pobladores y se conversa con los fundadores de la comunidad o sus dirigentes, no resulta difícil advertir expresiones recurrentes de autoconfianza colectiva, certidumbres sobre su disposición de un poder organizado, una cierta creencia en las capacidades de la comu- nidad para proponerse objetivos y unirse para su logro". (Franco, 1992)

En otra experiencia de carácter diferente en la Argentina las conclusiones son similares respecto al efecto potenciador de grandes proporciones que puede tener el crecimiento de la autoestima en la cultura de la comunidad. Señala Gastón Bordelois (1995) respecto al "Programa social agropecuario" que a través del mismo se reconoce a los pequeños productores minifundistas organizados en grupos "capacidad no sólo para identificar sus problemas sino también de aportar soluciones, asumiendo el protagonismo correspondiente. Se les hace descubrir una instancia de autovaloración que resulta trascendente para la afirmación personal y grupal". Los resultados son sorprendentes según informa el autor que es el Coordinador del programa: "Resulta una experiencia que nos impacta y conmueve ver de qué manera estos pobladores rurales que viven en situaciones socioeconómicas críticas se motivan con la posibilidad de trabajar mancomunadamente en procura de una mejora de sus niveles de vida contando con modestas ayudas económicas y técnicas. Es que han sido recordadas y reconocidas su existencia y sus necesidades, y se les ha dado el espacio necesario para que puedan volcar sus aportes y esfuerzos personales participando activamente en el proceso de cambio. Son, en definitiva, valorados como personas y se les reconoce su capacidad de asumir un rol protagónico y ser corresponsables en la tarea de su propia elevación. Se advierte un cambio total en la actitud que esas personas tienen con respecto al resto de la 
sociedad, a sl mismos, y frente a sus familias".

e. La acción cultural puede complementar y ampliar la labor de la escuela pública, actualmente con graves insuficiencias en las áreas pobres. Se observa el avance de serios déficits ligados a temas como el descenso del gasto educativo real, y la ampliación de la brecha de inequidad. Informes del Banco Mundial indican que entre otros aspectos: "la calidad promedio de la educación primaria en América Latina es funesta... La baja calidad del sistema educativo se refleja en el alto nivel de repetición uno de los más altos del mundo en desarrollo". (Banco Mundial 1995) Según una encuesta reciente del Ministerio de Educación del Brasil (1996) el 70\% de los estudiantes brasileños de secundaria no saben hacer operaciones básicas de matemáticas, y la mitad de los mismos es incapaz de formular un juicio propio de los textos que lee.

La labor cultural puede extender considerablemente el ámbito de acción de la tarea educativa. Los espacios culturales pueden motivar y atraer a sectores que han abandonado la escuela. Desde la cultura puede ayudarse seriamente a tratar de mejorar aspectos centrales como el interés y actitudes hacia la lectura. Escuela y cultura con su bagaje de "marcos informales" de educación pueden constituir un equipo de trabajo que incida en los resultados finales.

f. La acción cultural puede cumplir significativos roles en la lucha por prevenir los alarmantes avances de la criminalidad en la región. La cultura puede ofrecer espacios realizadores a los contin- gentes de jóvenes que se hallan fuera del mercado de trabajo. Puede también proporcionarles marcos de pertenencia básicos, frente a la sensación de aislamiento social que con frecuencia viven. Asimismo, sus mensajes pueden reforzar valores positivos, y ayudar a contrarrestar influencias regresivas que están actuando sobre ellos.

g. La cultura, como lo indica la pionera línea de trabajo abierta al respecto por la red liderada por el Centro de Estudios Latinoamericanos de la Universidad de Maryland, es estratégica para el fortalecimiento efectivo del proceso democrático en la región. Construir una cultura para la democracia aparece, como lo señalan los documentos iniciales generados por la red, como un elemento sine qua non para su funcionamiento activo.

La cultura, como lo indican las áreas de exploración referidas, sólo ejemplificativas de una nómina que puede ser mucho más extensa, es una "inversión social" de consecuencias multiplicadoras en gran escala respecto a los problemas sociales del Continente. Es imprescindible reinstalar la cultura y sus posibilidades en la búsqueda de soluciones para los agobiantes problemas sociales de la región. Estamos en un continente excepcionalmente dotado en este plano. Como nos recuerda Carlos Fuentes "Alucinados por el progreso, creímos que avanzar era olvidar, dejar atrás las manifestaciones de lo mejor que hemos hecho: la cultura riquísima de un continente indio, europeo, negro, mestizo, mulato cuya creatividad aún no encuentra equivalencía económica, cuya continuidad 
aún no encuentra correspondencia política". (Fuentes, 1995)

\section{Referencias Bibliográficas}

Burki, Shadid Javed (1996). Disertación en Foro de Diálogo Interamericano. Was. hington.

Rosenthal, Gert (1995). El Tiempo, Bogotá, 11 de diciembre.

Fuentes, Carlos (1995). Imaginación y cambio. El País, Madrid, 23 de noviembre.

Cumbre Presidencial de las Américas, Miami (1994). Documento Final.

BID, Naciones Unidas. PNUD, (1995). Informe de la Comisión Latinoamericana y de Caribe sobre el Desarrollo Social.

Bellamy, Carol (1996). En Tercera Conferencia Americana sobre la Infancia. Chile, 9 de agosto.

Altimir, Oscar (1995). Inequality, employment and poverty in Latin America: an overview. CEPAL.

Tokman, Víctor E. (1996). Jobs and Solidarity. Main Challenges for the post-adjustment in Latin America. Development thinking and practice Conference. IDB, Washington, September.

Costa Fiho, Alfredo (1995). Un desarrollo social con nueva escala: nota sobre el espacio entre el gobierno y la empresa privada. Coloquio sobre una nueva generación de politicas de desarrollo. PNUD/DRALC.

Minujin, Alberto (1995). Squeezed: The middle class in Latin America. Environment and Urbanization. Vol. 7, No. 2.

Anderson, John (1996). Debtors disrobe in banking protest. The Washington Post, June 15.

New York Times (09-02-96). Data information resources.
Katzman, Rubén (1992). ¿Por qué los hombres son tan irresponsables? Revista de la CEPAL, abril de 1992.

Ratinoft, Luis C. (1996). Delincuencia y paz ciudadana. BID.

Wolfensohn, James (1996). El gasto social es clave. Clarín, Buenos Aires, 23 de febrero.

Senn, Amartya (1996). Development thinking at the beginning of the 21 st Century. Development thinking and practice Conference. IDB, September.

Birdsall, Nancy, et al. (1996). La desigualdad como limitación del crecimiento en América Latina. Gestión y Política Pública, CIDE, México.

Birdsall, Nancy (1996b). Smart ways to lend. The Journal of Commerce. June 27.

Cominetti, Rosella (1994). Gasto social y ajuste fiscal en América Latina. Gobierno de los Países Bajos/CEPAL.

Faigon. Jehoshua (1992). El voluntarismo en la sociedad israeli. Israel.

Kuttner, Robert (01-09-96). No market for civility. The Washington Post.

Franco, Carlos (1992). Imágenes de Villa El Salvador. Incluido en B. Kliksberg (comp.), ¿Cómo entrentar la pobreza?: aportes para la acción. Grupo Editor Latinoamericano, $2^{\mathrm{B}}$ edic.

Bordelois, Gastón (1995). Reflexiones desde una experiencia concreta. En Desarrollo Humano: un diálogo con la economía y las ciencias sociales. Programa Argentino de Desarrollo Humano.

Banco Mundial (1995). America Latina y la crisis mexicana: nuevos desafíos.

Ministerio de Educación (1996). Encuesta a Folha Sao Paulo, Julio.

Fuentes, Carlos (1995). Introducción al Informe de la Comisión Latinoamericana y del Caribe sobre el Desarroilo Social. 